This item was submitted to Loughborough's Research Repository by the author.

Items in Figshare are protected by copyright, with all rights reserved, unless otherwise indicated.

\title{
Scanning strategies and spacing effect on laser fusion of H13 tool steel powder using high power Nd : YAG pulsed laser
}

\section{PLEASE CITE THE PUBLISHED VERSION}

\section{PUBLISHER}

(C) Taylor \& Francis

\section{LICENCE}

CC BY-NC-ND 4.0

\section{REPOSITORY RECORD}

Beal, V.E., Poonjolai Erasenthiran, Neil Hopkinson, Phill M. Dickens, and Carlos Henrique Ahrens. 2019. "Scanning Strategies and Spacing Effect on Laser Fusion of H13 Tool Steel Powder Using High Power Nd: YAG Pulsed Laser". figshare. https://hdl.handle.net/2134/3498. 
This article was downloaded by:[Loughborough University]

On: 11 December 2007

Access Details: [subscription number 768487621]

Publisher: Taylor \& Francis

Informa Ltd Registered in England and Wales Registered Number: 1072954

Registered office: Mortimer House, 37-41 Mortimer Street, London W1T 3JH, UK

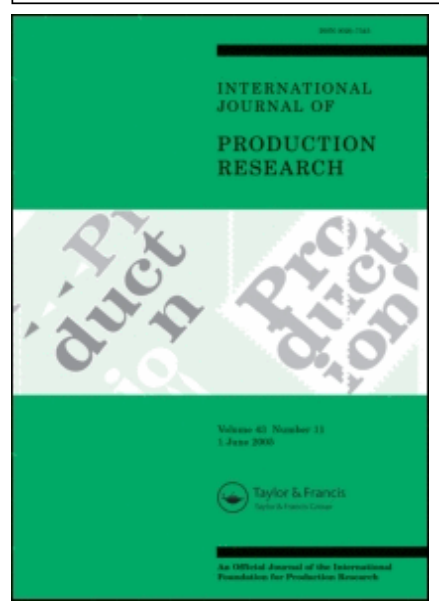

\section{International Journal of Production Research}

Publication details, including instructions for authors and subscription information: http://www.informaworld.com/smpp/title content=t713696255

Scanning strategies and spacing effect on laser fusion of $\mathrm{H} 13$ tool steel powder using high power Nd:YAG pulsed laser

V. E. Beal ${ }^{\text {a }}$; P. Erasenthiran ${ }^{\text {b}}$; N. Hopkinson ${ }^{\text {b}}$; P. Dickens ${ }^{\text {b }}$; C. H. Ahrens ${ }^{\text {a }}$

a Departamento de Engenharia Mecânica, Universidade Federal de Santa Catarina, Florianópolis, SC, Brazil

${ }^{\mathrm{b}}$ Rapid Manufacturing Research Group, Wolfson School of Mechanical and

Manufacturing Engineering, Loughborough University, Loughborough LE11 3TU, UK

First Published on: 24 February 2007

To cite this Article: Beal, V. E., Erasenthiran, P., Hopkinson, N., Dickens, P. and Ahrens, C. H. (2007) 'Scanning strategies and spacing effect on laser fusion of $\mathrm{H} 13$ tool steel powder using high power Nd:YAG pulsed laser', International Journal of Production Research, 46:1, 217 - 232

To link to this article: DOI: $10.1080 / 00207540500168279$

URL: http://dx.doi.org/10.1080/00207540500168279

\section{PLEASE SCROLL DOWN FOR ARTICLE}

Full terms and conditions of use: http://www.informaworld.com/terms-and-conditions-of-access.pdf

This article maybe used for research, teaching and private study purposes. Any substantial or systematic reproduction, re-distribution, re-selling, loan or sub-licensing, systematic supply or distribution in any form to anyone is expressly forbidden.

The publisher does not give any warranty express or implied or make any representation that the contents will be complete or accurate or up to date. The accuracy of any instructions, formulae and drug doses should be independently verified with primary sources. The publisher shall not be liable for any loss, actions, claims, proceedings, demand or costs or damages whatsoever or howsoever caused arising directly or indirectly in connection with or arising out of the use of this material. 


\title{
Scanning strategies and spacing effect on laser fusion of H13 tool steel powder using high power Nd:YAG pulsed laser
}

\author{
V. E. BEAL*†, P. ERASENTHIRANt, N. HOPKINSONt, \\ P. DICKENS $\ddagger$ and C. H. AHRENS $\dagger$ \\ †Universidade Federal de Santa Catarina, Departamento de Engenharia Mecânica, POSMEC, \\ Caixa Postal 476, Campus Universitário, Trindade, Florianópolis, SC, 88040900, Brazil \\ $\$$ Rapid Manufacturing Research Group, Wolfson School of Mechanical and Manufacturing \\ Engineering, Loughborough University, Loughborough LE11 3TU, UK
}

(Revision received April 2005)

\begin{abstract}
Layered manufacturing technologies have been used to produce complex parts of diversified materials through different physical/chemical manufacturing principles. Nevertheless only a few materials are commercially available to build parts suitable for engineering applications. In this paper, the powder fusion of $\mathrm{H} 13$ tool steel is investigated. A high power Nd:YAG pulsed laser source on a $\mathrm{CNC}$ machine was used to fuse the powder, layer by layer, building solid cubes for further analysis. Four different laser vector scanning strategies were evaluated by comparing the results of porosity and layer distortion. The complexity of the laser/powder interaction shows that a complex strategy must be used to avoid porosity and distortion.
\end{abstract}

Keywords: Laser fusion; Rapid manufacturing; Tool steel

\section{Introduction}

The search for time and cost reduction for the development and manufacturing of new products has been pushing rapid prototyping and manufacturing (RP\&M) through new technical areas in the understanding of additive processes and materials. RP\&M has the advantage of producing highly complex parts without expensive tools and long machine setups. On the other hand, precision, resolution and materials are the current limitations of these technologies.

An application of layer manufacturing is building moulds that can be used for injection moulding. As complexity is virtually free, these moulds can be designed and built with conformal cooling channels (Dalgarno and Stewart 2001). However, a few materials are available and at present they do not have satisfactory properties. Most of the RP\&M processes that produce moulds and components with metals are based on laser powder fusion/sintering. The low number of materials available is mainly due to the complexity in identifying suitable laser and process parameters which can produce parts. At present, researchers around the globe are working on

*Corresponding author. Email: valterbeal@gmail.com 
various aspects of this complex process, such as powder deposition techniques (Kumar et al. 2004, Yang and Evans 2004) and pre-heating and laser-material interaction phenomena (Fischer et al. 2003, Tolochko et al. 2003, Dai et al. 2004).

Among various materials that are traditionally used for fabricating tools using conventional techniques, H13 tool steel has good fatigue resistance under thermal cycling. It is considered a suitable material for high durability moulds that require excellent surface finish and close tolerances (Norton 1996).

In this work, a high power $(500 \mathrm{~W}) \mathrm{Nd}$ :YAG pulsed laser was used to build small specimens of $\mathrm{H} 13$ tool steel. The main aim of this work is to understand the effect of laser vector strategies on the dimensional accuracy of layers and the specimen porosity. Different scan spacings were also evaluated in order to understand the interaction between laser vector scanning strategies and spacing. The results are presented and discussed. The microstructures of parts were also studied.

\section{Background}

RP\&M technologies are based on layer by layer deposition. Each layer is processed and added over a previous layer until the complete formation of a 3D object. Some of these technologies such as selective laser sintering (SLS), laser cladding and direct metal laser sintering (DMLS) can be used to build metallic parts.

SLS works with fine layers of powder deposited over a platform. Each layer is selectively sintered using a $\mathrm{CO}_{2}$ laser and a scanning mirror. After each layer is sintered, the platform is lowered and a new layer of powder is spread over the previous one. The laser beam sinters a new layer adding it to the previous one and the process is repeated until the complete part is built. SLS uses a metallic powder coated with a thermoplastic binder. The laser melts the binder and as it solidifies it holds the metal powder together to form the geometry of the part. Subsequent steps, after the part being geometrically built by the machine, are binder removal, pre-sintering, sintering and copper/bronze infiltration. These steps are carried out in furnaces with controlled temperature and environment. At present, materials being used are 54\% 420 stainless steel and $46 \%$ bronze, $60 \% 420$ stainless steel and 40\% bronze and an A6 steel version (3D Systems 2004).

DMLS is similar to SLS but it uses the power of the laser to melt a low melt point alloy using liquid phase sintering to create a 3D part, without the necessity for special post-processing in an oven to increase the density of the part. Nevertheless, the parts can have lower mechanical properties compared to those obtained by selective laser sintering (Storch et al. 2003). There are two materials currently available for this process, a nickel/bronze/copper phosphate mix and a steel alloy.

Laser cladding is a process where the powder is sprayed or fed coaxially with a shield gas over a high power density laser spot. Laser cladding is successful in cladding wide varieties of materials. Many researchers have built parts with Ti-6Al-2Sn-4Zr-2MO, Ti-48Al-2Cr-2Nb, Ti-22Al-23Nb and steel such as H13 (Atwood et al. 1998, Lü et al. 2001, Ensz et al. 2002). This technique can be used 
for building full dense parts. Unfortunately, parts made by this technology have geometric limitations and low tolerances. It is usually necessary to perform milling operations after building the part; however, researchers are working on improving the process (Atwood et al. 1998, Lü et al. 2001).

Researchers have been studying different materials that can be processed by these powder processes. At Liverpool University full dense stainless steel (316L) parts have been made using nanosecond pulsed Nd:YAG lasers by direct metal laser re-melting (DMLR), a variation of the SLS process (Morgan et al. 2001). Porous thin walled structures with copper powder melting have also been made by this process (Pogson et al. 2003). The production of dense H10 tool steel parts and graded $\mathrm{H} 10$ with tungsten carbide was evaluated by $\mathrm{Su}$ (2002). Leong et al. (2002) produced copper matrix composites through laser sintering with a $\mathrm{CO}_{2}$ laser. Nickel alloy fusion was investigated by Abe et al. (2001) using two sources of laser energy, $\mathrm{CO}_{2}$ and $\mathrm{Nd}: \mathrm{YAG}$, with different strategies for pre-heat and re-heat of the material.

Powder processing using a laser is a complex process due to the various phenomena involved. The reflectivity and absorption of the laser by metallic materials is different from ceramics and polymers. The wavelength of an Nd:YAG laser $(1.06 \mu \mathrm{m})$ is generally more appropriate for processing metals and a $\mathrm{CO}_{2}(10.6 \mu \mathrm{m})$ laser works better with ceramics and polymers (Lü et al. 2001). Applying a laser beam over a powder can lead to sintering or fusion. Solid state sintering is a slow process which cannot be achieved easily by the short time interaction between the laser and material. One alternative is to use liquid phase sintering where a lower melting point alloy (during a stage of the sintering cycle) wets the solid particles thereby increasing the sintering rate and density. Nevertheless, this is not an easy process as surface tension and viscosity effects can result in undesirable balling and other effects. Due to the short time of laser interaction it is difficult for diffusion to occur between the liquid phase and solid phase (Agarwala et al. 1995). Completely melting the powder could provide the diffusion but also has many problems. As the alloys are completely melted and the fine grained microstructure of the powder is dissolved it is difficult to control the shrinkage and balling effect (Lü et al. 2001, Morgan et al. 2001).

To overcome these problems it is necessary to use a shielding atmosphere, to pre-heat the powder to higher temperatures, to use bimodal distributions of powders for optimum packing and to use additives to reduce surface tension (Agarwala et al. 1995). Another complementary action is to improve the laser strategies to reduce thermal stresses, porosity and shrinkage. Matsumoto et al. (2002) applied finite element analysis to optimize the thermal stress caused by the filling vector scanning pattern. The conclusion was to segment the pattern in smaller regions to avoid long vectors that could lead to distortion. This problem was also refereed to by Morgan et al. (2001) and called tearing. Dai and Shaw (2002) also used computational methods to evaluate different strategies to reduce layer distortion. In Pogson et al. (2003) a specific strategy was used to produce copper parts by DMLR.

The main advantage of using high power Nd:YAG laser is the higher penetration depth which is achievable due to high peak power density (with short pulses with high pulse energy). Nevertheless, the strategies and parameters used must be investigated to produce solid and useful parts. The aim of this work was to investigate how different laser scan strategies could influence the results for H13 powder 
when using a high power pulsed Nd:YAG laser. The spacing between the laser vectors and the thermal effects over the layer after the scan were also investigated.

\section{Methodology}

Based on the previously presented research, four strategies were selected for investigation using $-212 \mu \mathrm{m} \mathrm{H} 13$ powder. The first was the 'filling' strategy based on a pattern of consecutive parallel vectors presented in figure 1(a). The second strategy was a sequence of parallel vectors as shown in figure 1(b), denominated in this work as the 'sequential' strategy. The third strategy, known as 'alternated', is a pattern of alternated spaced vectors subdivided in two scan steps (figure 1(c)). The fourth strategy, 'refill' (as shown in figure 1(d)), was developed by Su (2002) where a powder refill between the vectors of the first and second set of scans was introduced.

The filling strategy (figure 1(a)) is the most common strategy used for laser marking and in various rapid prototyping systems. It is quick for area filling and has no dead time. It can cause a high thermal stress concentration as the regions of the layer can be overheated. The sequential strategy was used to avoid overheating by delivering the same amount of energy for the layer regions within a longer time. The alternated strategy had the same objective but far better in reducing the energy concentration on specific regions. Nevertheless, as evidenced in the previous work by Su (2002), spatter could remove material between the vectors using this strategy, so a refill strategy was developed to replace the material that was missing before applying the second set of raster scans, however it was a time consuming process. Spatter is the molten material that is ejected from the melt pool by the expansion of gases that are heated by the laser beam energy (Low et al. 2000). Due to this effect in laser fusion, material/powder loss occurs.

As the amount of porosity can be changed by using different laser scan spacing, two spacing distances between the vectors were evaluated for each strategy. The values of the spacing were 0.5 and $0.6 \mathrm{~mm}$ as shown in figure 2 . Increasing or decreasing the space between the vectors varies the overlapping of the scan lines. Increasing the spacing can lead to porosity as powder cannot be fused

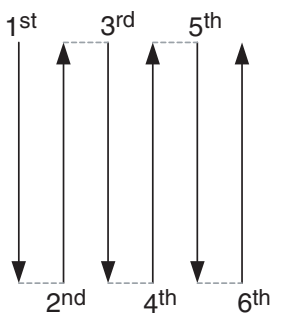

(a) Filling

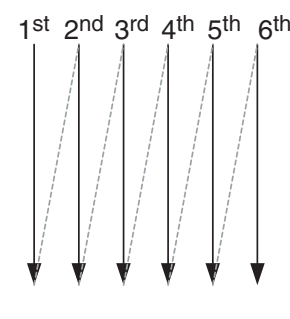

(b) Sequential

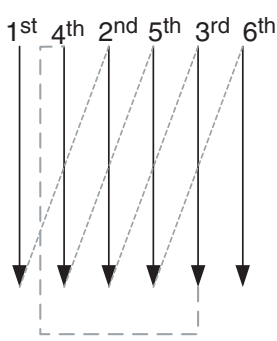

(c) Alternated

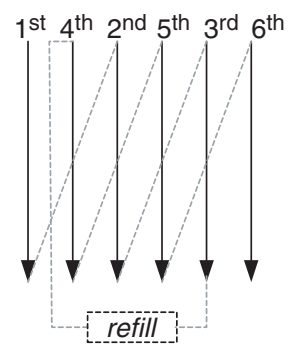

(d) Refill

Legend: __ laser action vector no laser-positioning

Figure 1. The laser scanning strategies studied. 

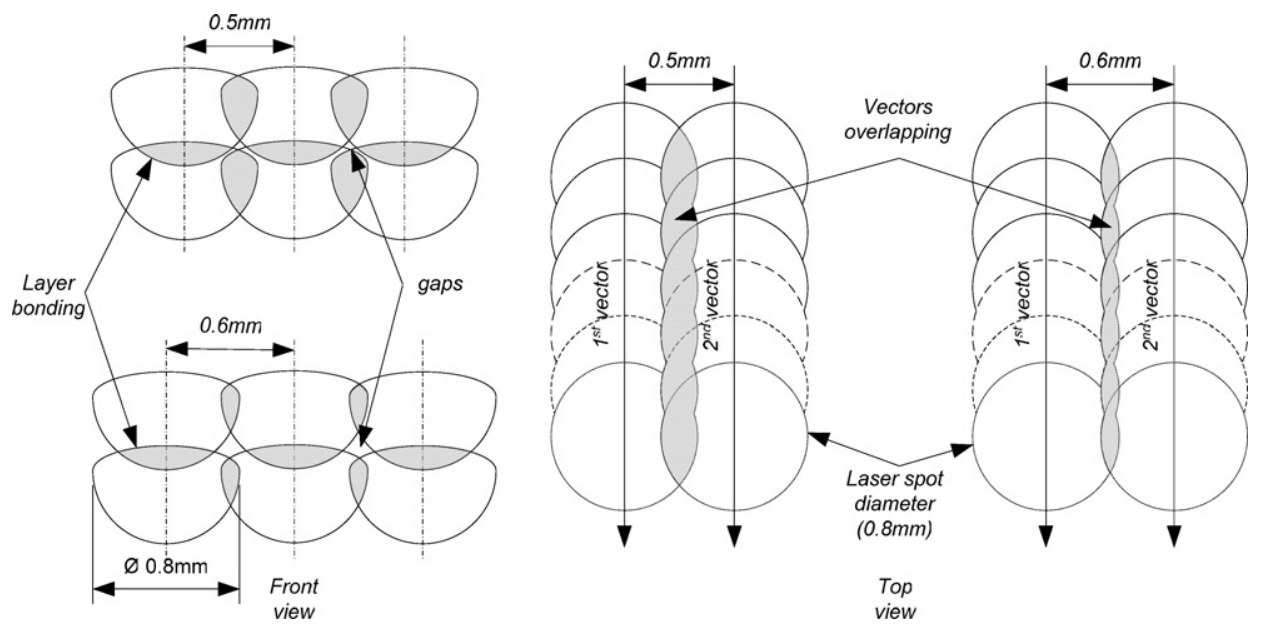

Figure 2. The different spacing used and their overlapping effect.

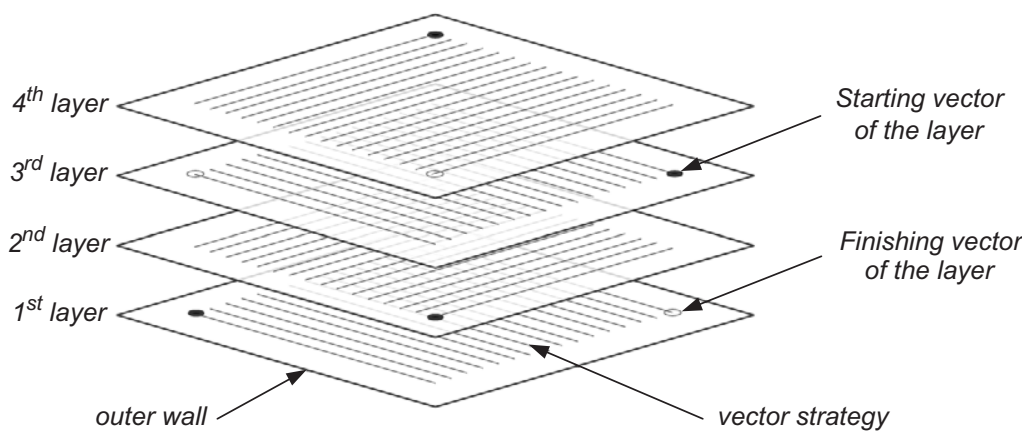

Figure 3. Cross-hatched vectors sketch and outer wall for sequential strategy (only four layers shown).

efficiently and gaps may occur between the scan lines. Decreasing the spacing can increase the time of layer manufacturing and thermal stresses due to the greater energy input. The spacing of $0.5 \mathrm{~mm}$ and $0.6 \mathrm{~mm}$ causes a theoretical linear overlap of $66.7 \%$ and $40 \%$ for each scan spacing respectively. It means that the $0.5 \mathrm{~mm}$ and $0.6 \mathrm{~mm}$ scan spacing produces $0.3 \mathrm{~mm}$ and $0.2 \mathrm{~mm}$ overlap between the centres of two fused beads.

The specimens were built within an outer wall that was offset by $1 \mathrm{~mm}$. This outer wall was made using single scan lines as these are usually unaffected by spattering and layer contraction. This wall worked as a dimensional reference for the specimen contraction. Subsequent specimen layers were scanned with the vector direction rotated through $90^{\circ}$ to avoid high anisotropy in the vector scanning direction. Figure 3 shows a sketch of the cross hatched vectors and outer contour for the sequential strategy.

Experiments were undertaken to build specimens of $9.8 \times 9.8 \times 3 \mathrm{~mm}$. They were built using fixed frames to set the layer thickness and layers were added and spread 


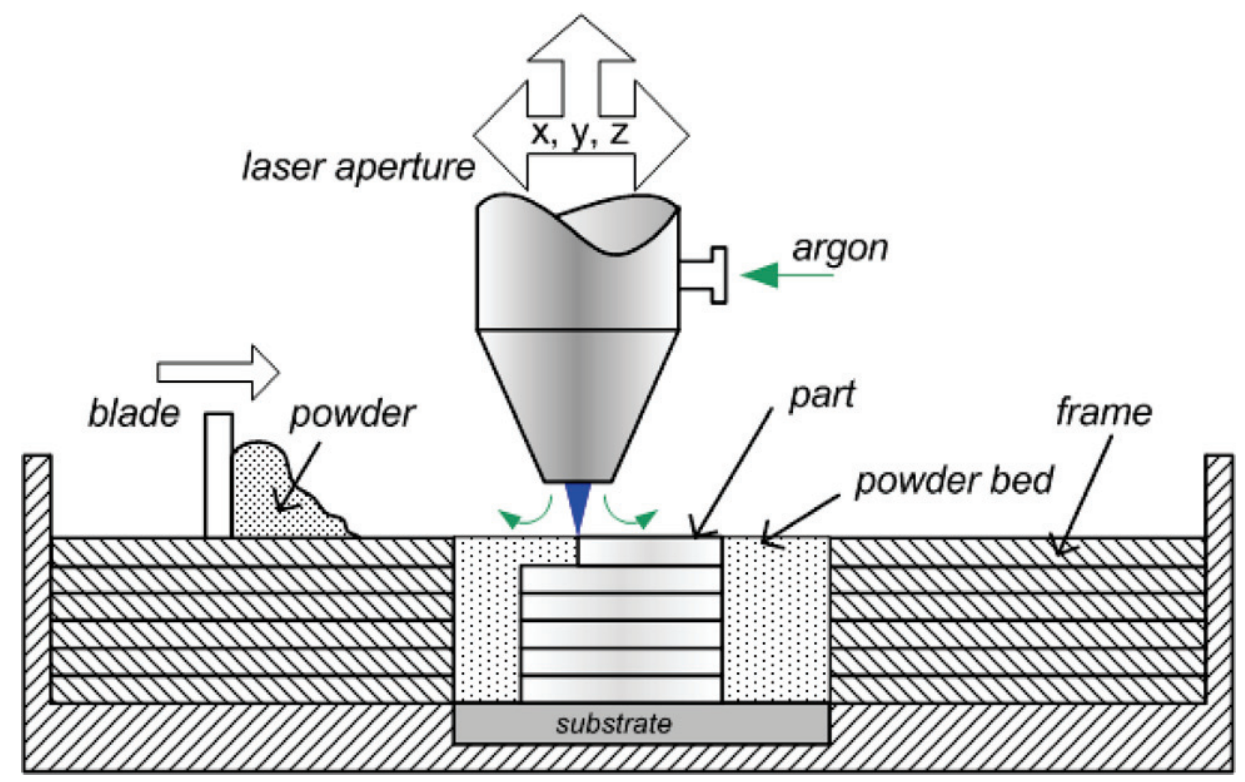

Figure 4. Schematic diagram of the experimental set-up.

with a blade manually. Then the laser scans a layer, a new frame was placed and powder spread for the subsequent layer using a blade. This process was repeated until the entire specimen was built. A schematic diagram of the set-up is shown in figure 4. A $550 \mathrm{~W}$ pulsed Nd:YAG laser (GSI Lumonics JK701H) was used to fuse the powder. The theoretical spot size was $0.8 \mathrm{~mm}$ and each layer had a thickness of $0.38 \mathrm{~mm}$. During the experiments a 15 litre/min local flow of argon was used to reduce oxidation.

The material used was H13 tool steel powder (percentage weights: Fe 90.8\%, C $0.32-0.42 \%$, Cr 4.75-5.25\%, Mn max. 0.4\%, Mo 1.25-1.75\%, Si 0.85-1.15\% and V $0.9-1.1 \%$ ) with a particle size distribution of $90 \%<22 \mu \mathrm{m}, 80 \%<16 \mu \mathrm{m}, 52 \%$ $<10 \mu \mathrm{m}$ and $15 \%<5 \mu \mathrm{m}$ (Osprey 2003). Figure 5 shows an SEM image of gas atomised $\mathrm{H} 13$ spherical powder.

All four strategies were used under constant laser processing parameters. Based on previous work developed by $\mathrm{Su}$ (2002), a $10 \mathrm{~J}$ pulse energy, pulse width of $5 \mathrm{~ms}$, pulse rate of $10 \mathrm{~Hz}$, scan speed of $200 \mathrm{~mm} / \mathrm{min}$, average laser power of $100 \mathrm{~W}$ and energy densities of $37.5 \mathrm{~J} / \mathrm{mm}^{2}$ were used to build the specimens. No pre-heat was used in the powder bed and it was fused at room temperature (about $22^{\circ} \mathrm{C}$ ).

To initially evaluate what strategy could deliver the lower porosity levels, two samples for each spacing/strategy combination were built resulting in eight specimens. These specimens were cross sectioned for further analysis of porosity and area. After determining what strategy was better in terms of porosity and cross section distortions, five samples for the vector line spacing of 0.5 and $0.6 \mathrm{~mm}$ were made.

To compare the thermal effect of the strategies over a manufactured layer, the temperature of specimens after the first layer build were measured. The temperature was taken using a thermal scanner (AGEMA 900). For this, $30 \times 30 \mathrm{~mm}$ layers 


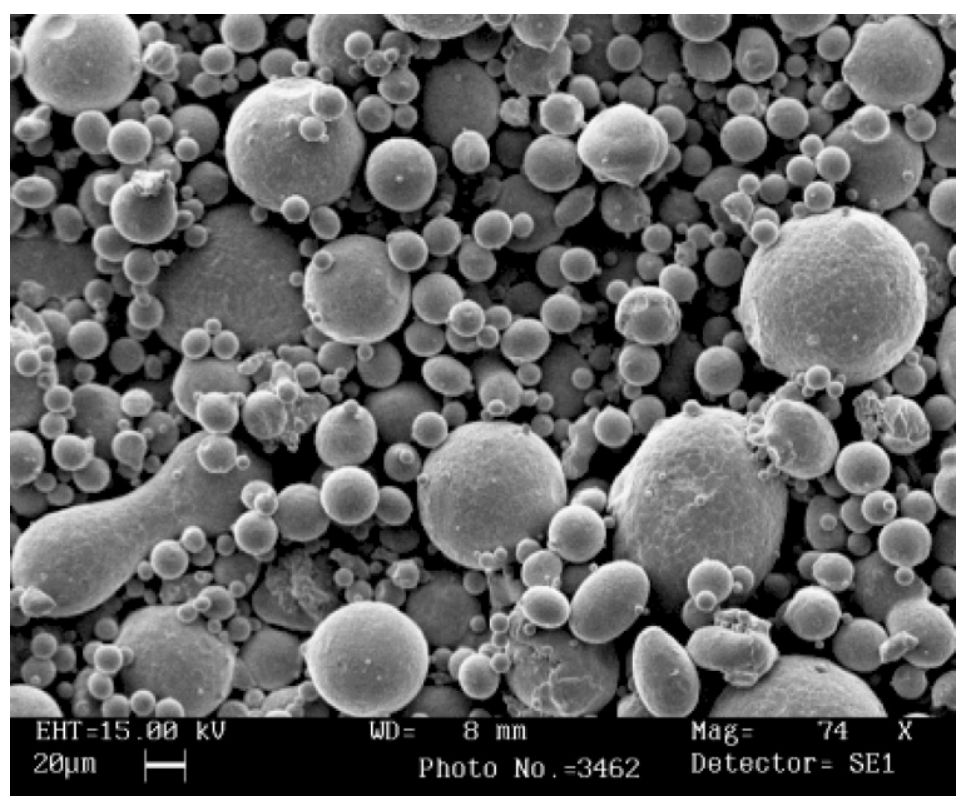

Figure 5. SEM image of the H13 powder.

were built. After the layer was completed a snapshot of the temperature was taken. The time to take the infrared picture after finishing the layer was between 5-15 seconds (time to turn off the laser and open the chamber to capture the thermal image). As metallic materials reflect the infrared radiation some adjustments must be made in the software to obtain accurate values of body temperature. Material, surface roughness and angle of incidence all affect the reflection of the infrared. Nevertheless, the values of the reflectivity of the powder were not available to adjust the infrared band of the camera to obtain the most accurate value. So the temperature distribution in the layers can only be used to compare each strategy of how heat is distributed over the layer but not to quantify the heat.

The specimens were cross sectioned, ground and polished with $1 \mu \mathrm{m}$ diamond abrasive. Macro pictures of the cross section with reference scales were taken for all specimens. After imaging treatment to set grey shades and black and white, the porosity and incomplete area were measured using Image Tool Version 3 software (UTHSCSA 2004). A scale measure of $1 \mathrm{~mm}$ was used as a reference and the layer areas were defined by the outer border contour of the specimens.

\section{Results and discussion}

The specimens built to determine the best strategy did not present a regular layer thickness. Figure 6 shows one of the specimens with $0.5 \mathrm{~mm}$ spacing using the refill strategy. In general, the specimens obtained using filling and sequential strategies showed a depression in the middle of the specimen. In the alternated strategy the scanning pattern was perceptible. The most uniform specimens were produced with the refill strategy. Figure 7 shows the top view from specimens obtained with 


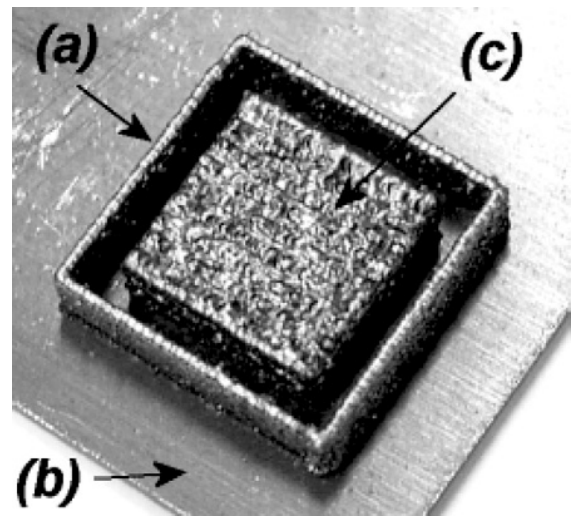

Figure 6. A typical result: (a) outer border, (b) substrate and (c) specimen.

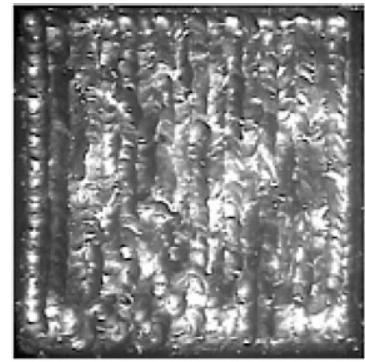

filling

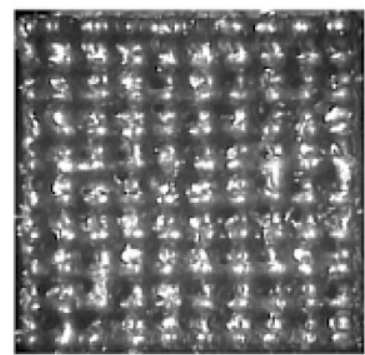

alternated

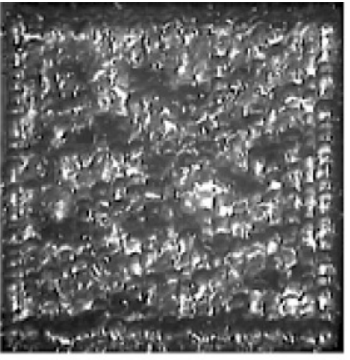

sequential

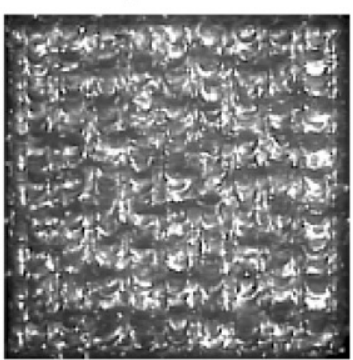

refill

Figure 7. Top view of the specimens obtained using different strategies $(0.5 \mathrm{~mm}$ spacing).

$0.5 \mathrm{~mm}$ spacing for all strategies. Spatter and balling were identified during the manufacturing of these specimens.

The cross sections of these specimens showed that changing the spacing had a minimum influence over the porosity for all the strategies studied. Alternated strategy showed the highest porosity, approximately $15 \%$ of the cross section area. Filling, sequential and refill showed low porosity, 2.6\%, 5\% and 3\% respectively, which can be considered a normal porosity value for powder metallurgy parts (German 1994).

The porosity of the specimens was mainly formed by large pores (greater than $10 \mu \mathrm{m})$. It was noticeable that pores appeared between the laser scans and between 


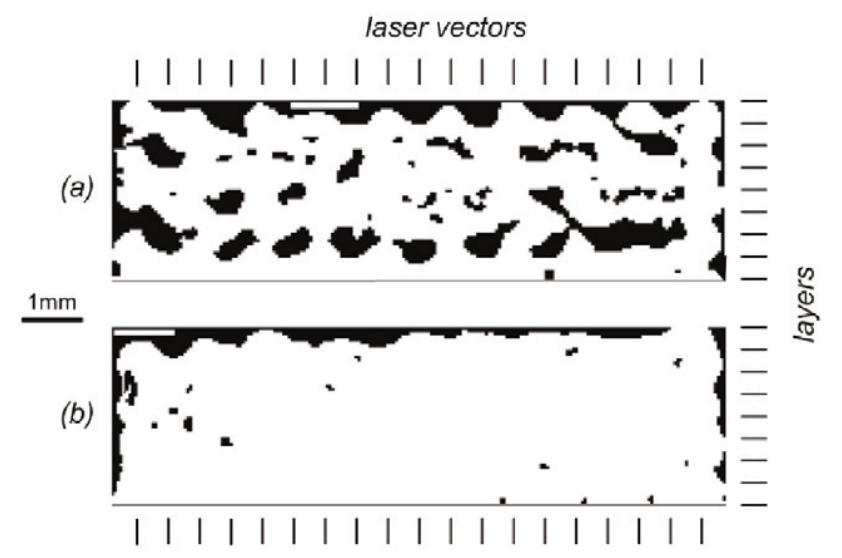

Figure 8. A perceptible pore pattern in the alternated (a) strategy in contrast with refill (b).

the layers. This pore formation was greater in the alternated strategy. Also, the pores found with this strategy were distributed on a hatch pattern. This phenomena occurred because spatter and powder melting of two largely spaced vectors (without overlapping) left the space between them with less powder or/and without powder to fuse in the next (alternated) scan between the two first vectors. However in the refill strategy, the powder loss was replaced before the next (alternated) scan. For filling and alternated as the vectors are drawn side-by-side, the next vector pulled powder from the surrounding area which was not fused yet. This was the main cause of the depression in the middle of the cross sections (not at the corner) of the specimens produced by these strategies. This can be justified by rotating the scanning direction for each layer build. Figure 8 shows cross-sections of two different specimens. The top picture is a cross section of a specimen built by the alternated strategy (figure 8(a)). The specimen in figure 8 (b) was built with the refill. Both were made using $0.5 \mathrm{~mm}$ of spacing. The images show only the contrast of the cross sections that were used to measure the pore area.

The amount of porosity is one of the problems that can occur when fusing powder through high power pulse lasers due to incomplete melting of the powder, trapped gases and the spatter effect. To measure the amount of material mass loss caused by the spatter effect, a simple experiment was designed. Substrates with square grooves of $500 \mu \mathrm{m}$ depth were used to spread the powder and fuse four lines of powder. The mass of the substrates (M1), the mass of the substrates plus added $500 \mu \mathrm{m}$ powder layers (M2), the mass of the substrates with the powder and the fused lines (M3) and the mass of the substrates with only the fused lines (M4) were measured. The lines were fused using the same parameters that were used for manufacturing the specimens (pulse energy of $10 \mathrm{~J}$, pulse width of $5 \mathrm{~ms}$, repetition rate of $10 \mathrm{~Hz}$ and federate of $200 \mathrm{~mm} / \mathrm{min}$ ). Figure 9 shows the sequence described above for the mass measurement. This experiment was repeated eight times in order to get the average value. It was found that there was a great difference between the mass of substrate with powder and laser fused lines to the substrate with powder layer before the laser fusion. 


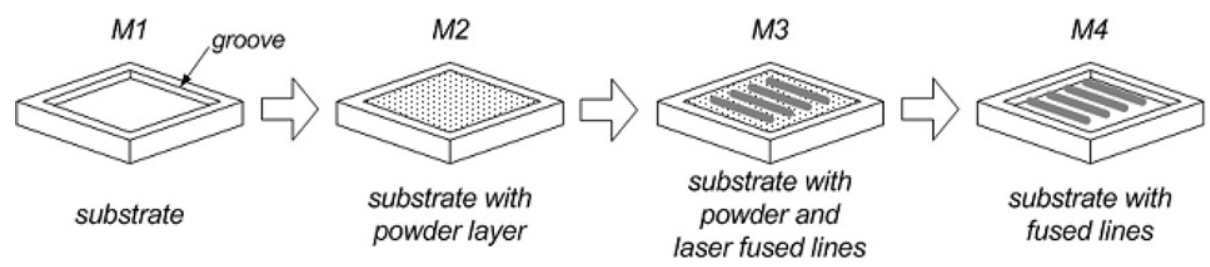

Figure 9. Measurement sequence for mass lost by spattering effect.

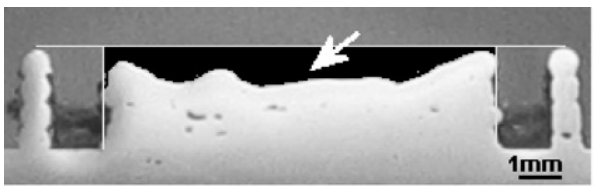

(a)

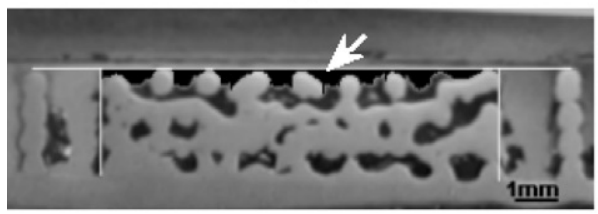

(c)

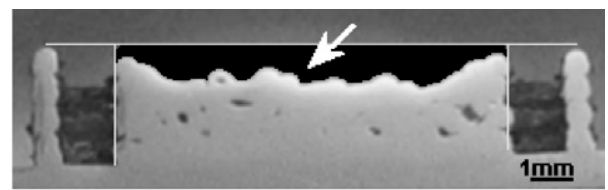

(b)

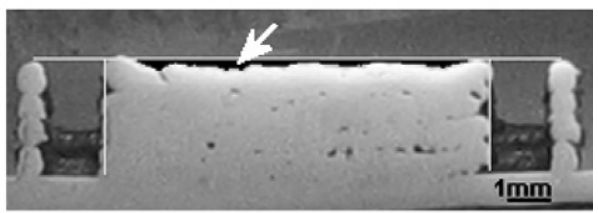

(d)

Figure 10. The cross section of specimens build with $0.5 \mathrm{~mm}$ spacing (a) filling, (b) sequential, (c) alternated and (d) refill (area lost is indicated in black).

The results showed that for eight repetitions, the average of mass lost was $18.8 \%$ (standard deviation 1.74\%). This volume reduction from the powder bed could have two sources: vaporization of the material and mainly by the spatter. The mass lost affected the shape of the specimens representing an overall volume reduction. This volume reduction was mainly characterised by the depression in the middle of the specimen. When the specimens were cross sectioned this volume reduction could be measured by the area missing from the cross section. The black area indicated in figure 10 was the evidence of mass lost for each strategy evaluated. It was perceptible that in the filling and sequential strategies as shown in figure 10 (both built with $0.5 \mathrm{~mm}$ ) these losses were more accentuated. The filling strategy had an average area reduction of $25.1 \%$, sequential $20.8 \%$ and alternated $10.6 \%$. As the refill strategy had the benefit of powder refill, it had the lowest value of volume reduction $(5.3 \%)$.

It was necessary to evaluate the overall result for each strategy. Pores and area reduction are both manufacturing defects that affect the material properties, so the summation of these describes the performance of each strategy and spacing. Table 1 summarizes the pores and area reduction percentages for the spacing and strategies evaluated. It is noticeable that except by the refill strategy all have present a high rate of cross section losses.

Based on the fact that the refill strategy presented the best results and no distinction was found between the spacings used an extra experiment, with five samples of each spacing with the refill strategy, was made to determine the variability of these results. All samples were cross sectioned, grounded, polished and 
Table 1. Porosity, area reduction and total area reduction from strategies and spacing.

\begin{tabular}{|c|c|c|c|c|c|c|}
\hline \multirow[b]{3}{*}{ Strategy } & \multicolumn{2}{|c|}{ Porosity } & \multicolumn{2}{|c|}{ Area reduction } & \multicolumn{2}{|c|}{ Total area reduction } \\
\hline & \multicolumn{2}{|c|}{ Spacing } & \multicolumn{2}{|c|}{ Spacing } & \multicolumn{2}{|c|}{ Spacing } \\
\hline & $0.5 \mathrm{~mm}$ & $0.6 \mathrm{~mm}$ & $0.5 \mathrm{~mm}$ & $0.6 \mathrm{~mm}$ & $0.5 \mathrm{~mm}$ & $0.6 \mathrm{~mm}$ \\
\hline Filling & $2.3 \%$ & $2.8 \%$ & $26.2 \%$ & $24.2 \%$ & $28.5 \%$ & $27.0 \%$ \\
\hline Sequential & $5.9 \%$ & $4.2 \%$ & $17.8 \%$ & $23.8 \%$ & $23.7 \%$ & $28.0 \%$ \\
\hline Alternated & $14.9 \%$ & $15.5 \%$ & $12.8 \%$ & $8.5 \%$ & $27.6 \%$ & $24.0 \%$ \\
\hline Refill & $3.6 \%$ & $2.3 \%$ & $4.8 \%$ & $5.8 \%$ & $8.4 \%$ & $8.1 \%$ \\
\hline
\end{tabular}
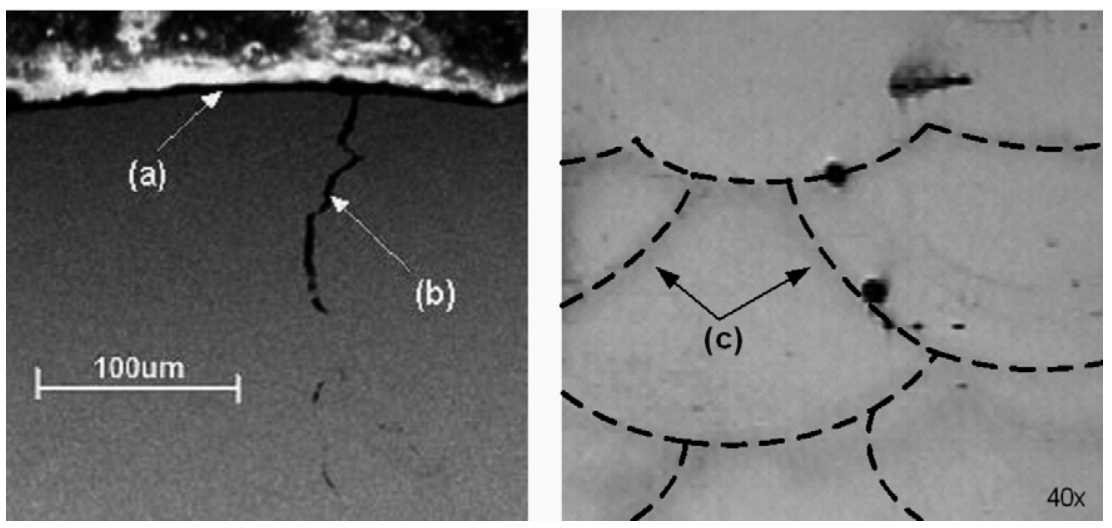

Figure 11. Crack across the scan direction, (b) top surface of the specimen (a) and re-heat marks (c).

analysed as previously. The average porosity found in the specimens produced with $0.5 \mathrm{~mm}$ of vector line spacing was $1.27 \%$ with a standard deviation of $0.95 \%$. For $0.6 \mathrm{~mm}$ of spacing, the average porosity was $2.1 \%$ with a standard deviation of $1.74 \%$.

The cross section of the specimens revealed not only pores but also cracks. These cracks were mainly along the scan direction as seen in figure 11 point (b). The rapid cooling from molten material to ambient temperature was possibly the main cause of the crack formations. As a large thermal gradient is present in the melt pool and the centre of the pool was the hottest and last region to solidify it cracked along the top of the bead. After polishing and etching the samples, the overlaps were also noticeable in the cross section as darker areas under the optical microscope. These areas were generated by the re-heat that occurred in the material from the previous layer (figure 11(c)). Pores were also trapped in these boundaries probably due to trapped gases.

The microstructure of the solidified material was consisted of dendrites of the H13 (figure 12). These dendrites are formed by rapid cooling and were orientated towards the centre of the laser spot.

The thermal images captured 5-15 seconds after the completion of each layer showed varying temperature levels as shown in figure 13(a), 14(a), 15(a) and 16(a). 


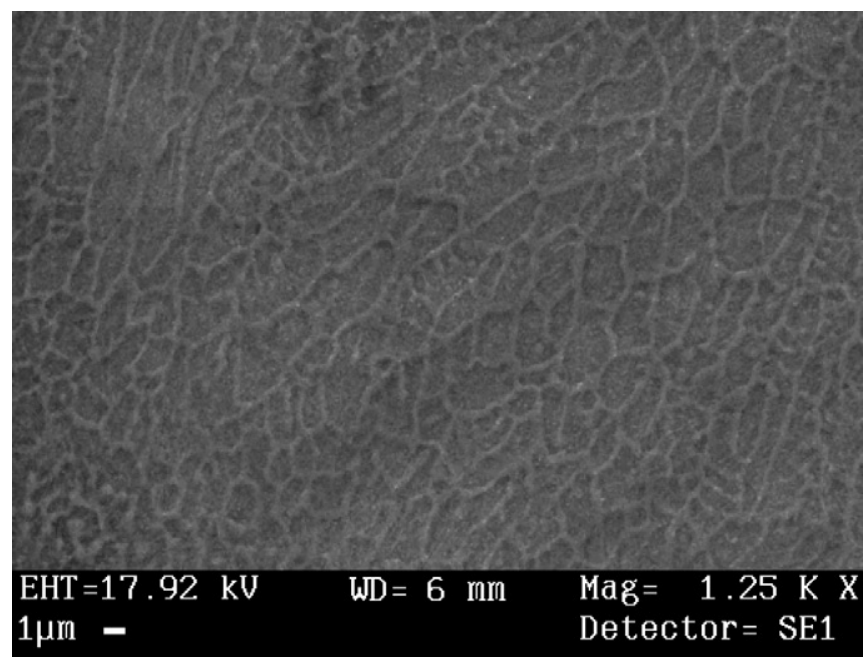

Figure 12. SEM image of the laser fused H13 microstructure.

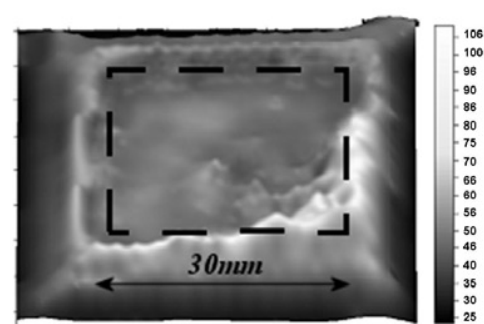

(a)

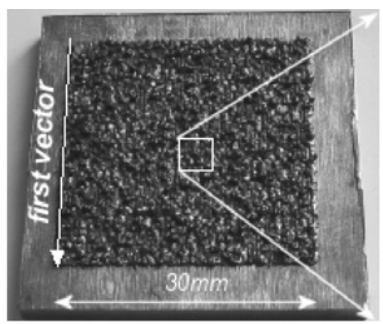

(b)

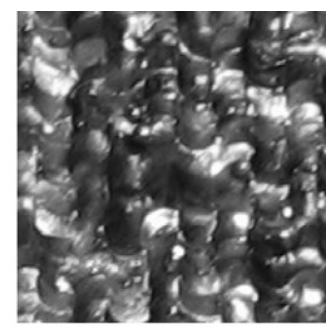

(c)

Figure 13. (a) 3D temperature map, (b) layer obtained and (c) detail of the layer surface for the filling strategy.

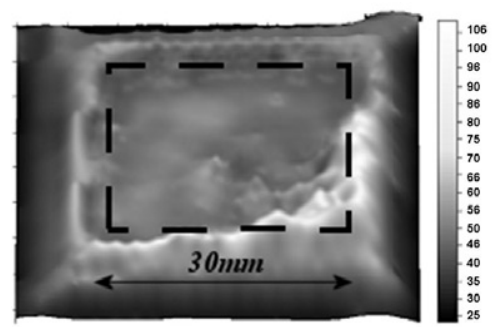

(a)

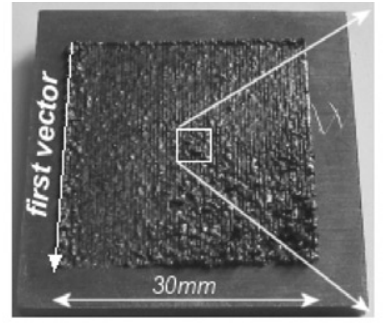

(b)

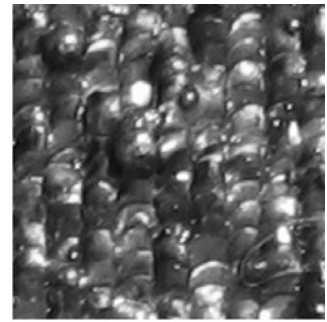

(c)

Figure 14. (a) 3D temperature map, (b) layer obtained and (c) detail of the layer surface for the sequential strategy.

The temperature scales from figure 13 to figure 16 are not meant to represent a comparative analysis between the strategies as the time to take the infrared pictures varied between them. However, they are useful as a reference for the temperature distribution over the layers. 


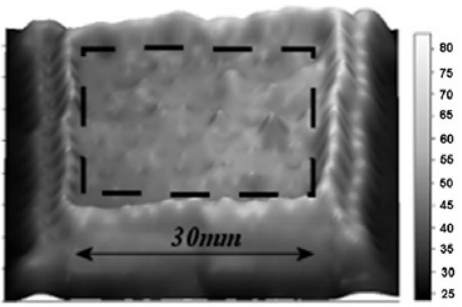

(a)

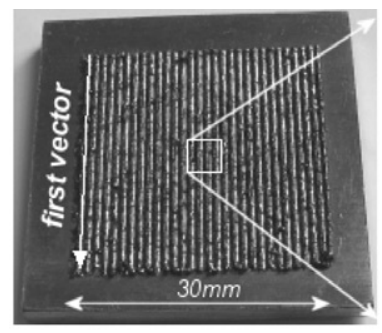

(b)

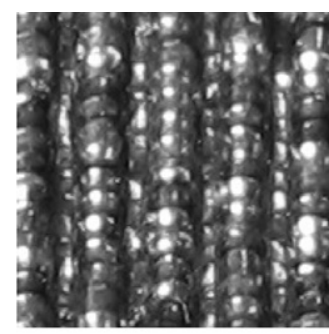

(c)

Figure 15. (a) 3D temperature map, (b) layer obtained and (c) detail of the layer surface for the alternate strategy.

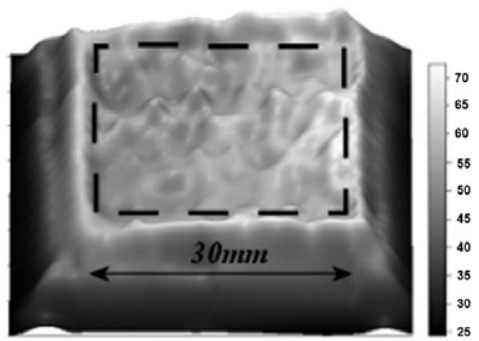

(a)

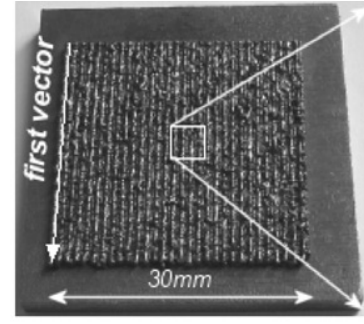

(b)

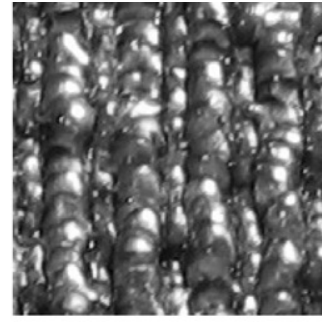

(c)

Figure 16. (a) 3D temperature map, (b) layer obtained and (c) detail of the layer surface for the refill strategy.

It was found that at this point, the highest temperature obtained was from the unaffected powder around the layer. This powder temperature was raised by the energy emitted from the plasma. The powder has low thermal conductivity due to low contact area between the particles, and hence it behaves as an insulator and does not cool down as quickly as the fused material. The brighter regions are the higher temperatures. The dash-lined squares in these pictures show the regions of the solidified layer. The higher temperatures around the squares are within the unaffected powder. The layers were built onto a metallic substrate (mild steel) which quickly lowered the temperature of the fused material.

For the filling strategy there were perceptible peaks of higher temperature over the layer. These peaks are probably the hotter spatter spots attached to the layer (figure 13(a)). The quality of the surface matched aspects of the thermal image. In the filling strategy spatter is noticed and makes the surface of the layer irregular as shown in figure 13(b) and surface detail in figure 11(c). In figure 13(b) the first vector of the layer and the surface detail region for figure 13(c) are indicated.

In the sequential strategy, spatter was also spotted but it was more concentrated in the corner produced last. Figure 14(a) shows the 3D temperature map where the end of the layer has elevated temperatures due to the concentrated spatter. Figure 14(b) shows the top view of the specimen where it could be seen that the end corner of the layer is irregular due to higher levels of spatter. 
The alternated strategy presented a more uniform temperature (figure 15(a)). It is reflected in its more uniform surface shown in figure 15(b) and figure 13(c) but with valleys between the scans.

The temperature over the surface of the refill strategy was almost uniform without spatter over the surface (figure 16(a)). A solid and uniform pattern and a thicker layer were observed in the refill strategy (figure 16(b) and (c)).

\section{Conclusions}

The laser interaction with the powder bed is a complex phenomena evidenced by the results obtained in this work. The spatter was one of the major problems for the strategies evaluated. Spatter ejected material from the melt pool reducing the amount of material fused and solidified in the part. The other effect was the melting and solidification of the powder itself. Although the filling strategy required less time to build a layer it showed a big problem with volume reduction and spatter deposited over the surface. The sequential strategy also had problems with the spatter but it was concentrated in a region of the layer towards the end of the process. This was not evidenced in the other strategies because of the alternated vectors that avoided spatter deposition in the layer surface.

As the refill strategy replaced the lost and contracted material it obviously showed the lowest porosity and volume reduction. Nevertheless it also had the longest build times due to the dead time between the vectors and the refilling. For comparison, to fuse a layer of $10 \times 10 \mathrm{~mm}$ using a spacing of $0.5 \mathrm{~mm}$ with $200 \mathrm{~mm} / \mathrm{min}$ of laser scan speed and $2000 \mathrm{~mm} / \mathrm{min}$ for table reposition (laser off), filling strategy takes about $1 \mathrm{~min}$, sequential strategy $1 \mathrm{~min} 10 \mathrm{~s}$, alternated strategy $1 \mathrm{~min} 13 \mathrm{~s}$ and refill strategy $1 \mathrm{~min} 23 \mathrm{~s}$. It is also important to point out that the laser parameters used in this work were not changed and different results might be obtained for other values. This laser parameter optimization will be carried out in future work.

The spacing change for the strategies showed little influence. Although the spacing differences evaluated was small, the $0.6 \mathrm{~mm}$ spacing showed a large variation and $0.5 \mathrm{~mm}$ proved to be more constant and in many results produced the lower porosity and volume reduction. The measurement of the area and pores was subjective even with attempts to keep all parameters constants. That is why the measurements were kept in percentages.

Other plans for future work are the use of bimodal distributions to increase the powder bed packing before applying the energy density, pre-heating the powder bed and using a pressurised shield gas such as nitrogen or helium to reduce plasma and spatter.

The porosity found in the refill strategy can be considered low depending on the application of the component produced with this process. Optimization for surface finish and dimensional control also need to be investigated.

\section{Acknowledgements}

The authors would like to thank CAPES (Brazilian Ministry of Education) and CNPq (Brazilian Ministry of Science and Technology) for the scholarship 
and support of the Ph.D. research student, the EPSRC, UK for the loan equipments and Osprey Metal Powders for the in kind contribution of materials.

\section{References}

3D Systems Website, LaserForm datasheets. Available online at: http://www.3dsystems.com (accessed February 2004).

Abe, F., Osakada, K., Shiomi, M., Uematsu, K. and Matsumoto, M., The manufacturing of hard tools from metallic powders by selective laser sintering. J. Mat. Proc. Tech., 2001, 111, 210-213.

Agarwala, M., Bourell, D., Beamen, J., Marcus, H. and Barlow, J., Direct selective laser sintering of metals. Rapid Prototyping J., 1995, 1(1), 173-179.

Atwood, C., Griffith, L.H., Schlienger, E., Ensz, M., Smugeresky, J., Romero, T., Greene, D. and Reckaway, D., Laser engineering net shaping (LENS): a tool for direct fabrication of metal parts, in Proceedings of ICALEO'98 Conference, Orlando, FL, USA, 1998, pp. E1-E7

Dai, K. and Shaw, L., Distortion minimisation of laser-processed components through control of laser scanning patterns. Rapid Prototyping J., 2002, 8(5), 270-276.

Dai, K., Li, X.-X. and Shaw, L.L., Comparisons between thermal modelling and experiments: effects of substrate preheating. Rapid Prototyping J., 2004, 10(1), $24-34$

Dalgarno, K. and Stewart, T., Production tooling for polymer moulding using the RapidSteel process. Rapid Prototyping J., 2001, 7(3), 173-179.

Ensz, M.T., Griffith, M.L. and Reckaway, D.E., Critical issues for functionally graded material deposition by laser engineered net shaping $\left(\right.$ LENS $\left.^{\circledR}\right)$, in Proceedings of the 2002 MPIF International Conference on Metal Powder Deposition for Rapid Manufacturing, San Antonio, TX, 2002, pp. ISBN 1-878954-87-3.

Fischer, P., Romano, V., Weber, H.P., Karapatis, N.P., Boillat, E. and Glardon, R., Sintering of commercially pure titanium powder with a Nd:YAG laser source. Acta Materialia, 2003, 51(6), 1651-1662.

German, R.M., Power Metallurgy Science, 1994 (MPIF: NJ, USA).

Kumar, P., Santosa, J.K., Beck, E. and Das, S., Direct-write deposition of fine powders through miniature hopper-nozzles for multi-material solid freeform fabrication. Rapid Prototyping J., 2004, 10(1), 14-23.

Leong, C.C., Lu, L., Fuh, J.Y.H. and Wong, Y.S., In-situ formation of copper matrix composites by laser sintering. Materials Science and Engineering: A, 2002, 338(1-2), 81-88.

Low, D.K.Y., Li, L. and Byrd, P.J., The effect of process parameters on spatter deposition in laser percussion drilling. Optics \& Laser Tech., 2000, 32, 347-354.

Lü, L., Fuh, J. and Wong, Y.S., Laser-induced materials and processes for rapid prototyping, 2001 (Kluwer Academic Publishers: Norwell, USA).

Matsumoto, M., Shiomi, M., Osakada, K. and Abe, F., Finite element analysis of single layer forming on metallic powder bed in rapid prototyping by selective laser processing. Int. J. Machine Tools \& Manuf., 2002, 42, 61-67.

Morgan, R., Sutcliffe, C.J. and O'Neill, W., Experimental investigation of nanosecond pulsed Nd:YAG laser re-melted re-placed powder beds. Rapid Prototyping J., 2001, 7(3), 159-172.

Norton, R.L., Machine design: an integrated approach, 1996 (Prentice-Hall Inc: NJ, USA).

Osprey Metal Powders Website, Microfine powder-H13 datasheets. Available online at: http://www.ospreymetals.co.uk (accessed November 2003).

Pogson, S.R., Fox, P., Sutcliffe, C.J. and O'Neill, W., The production of copper parts using DMLR. Rapid Prototyping J., 2003, 9(5), 334-343. 
Storch, S., Nelessen, D., Shaefer, G. and Rieter, R., Selective laser sintering: qualifying analysis of metal based powder systems for automotive applications. Rapid Prototyping J., 2003, 9(4), 240-251.

$\mathrm{Su}$, W., Layered fabrication of tool steel and functionally graded materials with a Nd:YAG pulsed laser. PhD thesis, Loughborough University, Loughborough, UK, 2002.

Tolochko, N.K., Arshinov, M.K., Gusarov, A.V., Titov, V.I., Laoui, T. and Froyen, L., Mechanisms of selective laser sintering and heat transfer in Ti powder. Rapid Prototyping J., 2003, 9(5), 314-326.

UTHSCSA Website, The University of Texas Health Science Center at San Antonio, ImageTool Version 3.0. Available online at: http://ddsdx.uthscsa.edu/dig/itdesc.html (accessed January 2004).

Yang, S. and Evans, J.R.G., Acoustic control of powder dispensing in open tubes. Powder Technology, 2004, 139, 55-60. 